\title{
CHEMICAL CONSTITUENTS FROM RED ALGAE Bostrychia radicans (Rhodomelaceae): NEW AMIDES AND PHENOLIC COMPOUNDS ${ }^{\#}$
}

\author{
Ana Lígia Leandrini de Oliveira, Denise B. da Silva, Norberto P. Lopes e Hosana M. Debonsi* \\ Departamento de Física e Química, Faculdade de Ciências Farmacêuticas de Ribeirão Preto, Universidade de São Paulo, \\ Av. do Café, s/n, 14040-903 Ribeirão Preto - SP, Brasil \\ Nair S. Yokoya \\ Seção de Ficologia, Instituto de Botânica, Av. Miguel Estefano, 3687, 04301-902 São Paulo - SP, Brasil
}

Recebido em 25/5/12; aceito em 14/9/12; publicado na web 9/11/12

\begin{abstract}
This study describes the isolation and structural determination of two amides, isolated for the first time: $N, 4-$ dihydroxy- $N$ - $\left(2^{\prime}\right.$ hydroxyethyl)-benzamide $(0.019 \%)$ and $N, 4$-dihydroxy- $N$-(2'-hydroxyethyl)-benzeneacetamide $(0.023 \%)$. These amides, produced by the red macroalgae Bostrychia radicans, had their structures assigned by NMR spectral data and MS analyses. In addition, this chemical study led to the isolation of cholesterol, heptadecane, squalene, trans-phytol, neophytadiene, tetradecanoic and hexadecanoic acids, methyl hexadecanoate and methyl 9-octadecenoate, 4-(methoxymethyl)-phenol, 4-hydroxybenzaldehyde, methyl 4-hydroxybenzeneacetate, methyl 2-hydroxy-3-(4-hydroxyphenyl)-propanoate, hydroquinone, methyl 4-hydroxymandelate, methyl 4-hydroxybenzoate, 4-hydroxybenzeneacetic acid and (4-hydroxyphenyl)-oxo-acetaldehyde. This is the first report concerning these compounds in B. radicans, contributing by illustrating the chemical diversity within the Rhodomelaceae family.
\end{abstract}

Keywords: Bostrychia radicans; marine algae; natural products.

\section{INTRODUCTION}

Bostrychia radicans (Montagne) Montagne is red seaweed belonging to the Rhodomelaceae (order Ceramiales) family, widely disseminated in tropical and warm temperate environments. ${ }^{1}$ In Brazilian littoral, this species occurs in estuarine systems associated with mangroves or in rocky intertidal habitats. ${ }^{2}$ Thus far, the species of Bostrychia genus have been extensively studied in terms of taxonomy, physiology and biogeography. ${ }^{1,3}$ Moreover, these species have received considerable molecular attention, leading to insights into its evolution, and nomenclatural revision. ${ }^{4,5}$ Concerning the chemical composition of Bostrychia species, previous studies have only reported the occurrence and chemotaxonomic implications of its polyols and low-molecular-mass carbohydrates ${ }^{6-9}$ In this context, polysaccharides isolated from Bostrychia montagnei Harvey were characterized ${ }^{10}$ while the antiherpetic and anticoagulant activities of these compounds were reported by Duarte. ${ }^{11}$ Moreover, two aromatic compounds were isolated from the alga Bostrychia tenella, namely, the new sulfated metabolite potassium 4-(hydroxymethyl)-benzenesulfonate and the compound 1-methoxyphenethyl alcohol. ${ }^{12}$ However, research regarding the secondary metabolism of Bostrychia species remains scarce in the literature. Against this background, the present study aimed to describe the chemical investigation of red algae $B$. radicans, yielding the isolation and structural elucidation of 20 compounds, including two amides: $N$,4-dihydroxy- $N$-(2'-hydroxyethyl)-benzamide and $N$,4-dihydroxy$N$-(2'-hydroxyethyl)-benzeneacetamide, both of which were isolated for the first time as natural products from the marine environment.

\section{RESULTS AND DISCUSSION}

Extensive studies focused on the structural diversity and biological potential of Bostrychia species have been carried out by our research group. To this end, specimens of the red macroalgae

*e-mail: hosana@fcfrp.usp.br

\#Artigo em homenagem ao Prof. Otto R. Gottlieb (31/8/1920-19/6/2011)
Bostrychia radicans (Rhodomelaceae) were collected in different ecosystems found in Ubatuba, the north littoral of São Paulo State, more specifically from Praia Dura rocky shore and Rio Escuro mangrove. The comparative analyses of Bostrychia species' volatile constituents revealed the effect of different habitats on the organism's metabolism, and provided some indicators which allowed us to outline several ecological considerations. ${ }^{13}$ However, no significant differences in chemical profile of polar and non-polar extracts or fractions of species collected from diverse environments were observed (unpublished data). The present work reports new complementary data regarding chemical constituents from red algae Bostrychia radicans. In this study, chromatographic fractionation of methanolic extract from $B$. radicans resulted in the isolation of two new amides: $N$,4-dihydroxy- $N$-(2'-hydroxyethyl)-benzamide (1) and $N$,4-dihydroxy- $N$-(2'-hydroxyethyl)-benzeneacetamide (2), Figure 1.<smiles>O=C(c1ccc(O)cc1)N(O)CCO</smiles>

1

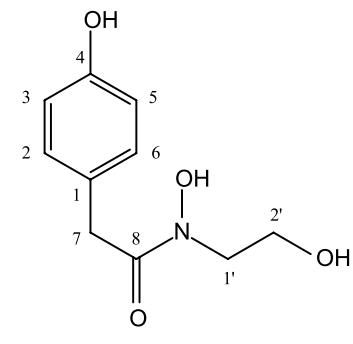

2
Figure 1. Amides: N,4-dihydroxy-N-(2'-hydroxyethyl)-benzamide (1) and $N, 4$-dihydroxy- $N-(2$ '-hydroxyethyl)-benzeneacetamide (2), isolated from $B$. radicans

Compound 1 was obtained as a colorless amorphous solid. The molecular formula $\mathrm{C}_{9} \mathrm{H}_{11} \mathrm{NO}_{4}$ was established by the ion at $\mathrm{m} / \mathrm{z}$ 198.0774 $[\mathrm{M}+\mathrm{H}]^{+}$in the HRESIMS spectrum. Theoretical mass of this compound is 198.0760 (error: $7.0 \mathrm{ppm}$ ). TLC analyses were performed and by the use of ninhydrin for staining, nitrogen presence was confirmed for both compounds. The ${ }^{1} \mathrm{H}$ NMR spectrum analysis 
Table 1. ${ }^{1} \mathrm{H}(500 \mathrm{MHz})$ and ${ }^{13} \mathrm{C}(125 \mathrm{MHz}) \mathrm{NMR}$ data of compounds $\mathbf{1}$ and 2 in $\mathrm{CD}_{3} \mathrm{OD}$. Chemical shifts are presented in $\delta$ (ppm) and coupling constants $J$ $(\mathrm{Hz})$ presented in parenthesis

\begin{tabular}{|c|c|c|c|c|c|c|}
\hline \multirow{2}{*}{$\mathrm{C}$} & \multicolumn{3}{|c|}{ Compound 1} & \multicolumn{3}{|c|}{ Compound 2} \\
\hline & ${ }^{13} \mathrm{C}$ & ${ }^{1} \mathrm{H}$ & HMBC & ${ }^{13} \mathrm{C}$ & ${ }^{1} \mathrm{H}$ & HMBC \\
\hline 1 & 123.7 & - & H-3 & 127.4 & - & H-3; H-5 \\
\hline 2,6 & 132.9 & $7.89(d ; 8.6)$ & $\mathrm{H}-2$ & 130.8 & $7.09(d ; 8.5)$ & H-2; H-3; H-5 \\
\hline 3,5 & 115.9 & $6.83(d ; 8.6)$ & H-3 & 116.0 & $6.72(d ; 8.5)$ & \\
\hline 4 & 163.0 & - & H-2; H-3 & 157.0 & - & H-2; H-3 \\
\hline 7 & 170.9 & - & H-2 & 41.8 & $3.46(s)$ & H-2 \\
\hline 8 & - & - & & 177.8 & - & $\mathrm{H}-7$ \\
\hline $1^{\prime}$ & 57.2 & $3.20(t ; 4.9)$ & H-2' & 56.8 & $3.26(t ; 5.3)$ & H-2' \\
\hline $2^{\prime}$ & 57.9 & $3.84(t ; 4.9)$ & H-1' & 57.2 & $3.84(t ; 5.3)$ & \\
\hline
\end{tabular}

revealed the presence of a pair of doublets at $\delta 7.89\left(\mathrm{~d}, J_{2,3} 8.6 \mathrm{~Hz} ; \mathrm{H}-2\right.$ and H-6) and $\delta 6.83$ (d, $J_{3,2} 8.6 \mathrm{~Hz} ; \mathrm{H}-3$ and H-5), each integrating to two hydrogen, suggesting the presence of two aromatic hydrogen in ortho position (Table 1). Therefore, these data indicates the presence of a para-disubstituted ring. The HMQC data demonstrate that these hydrogens are attached to carbons at $\delta 132.9$ and $\delta 115.9$, respectively. The HMBC correlation observed between the hydrogens at $\delta 6.83$ and the carbon at $\mathrm{d} 163.0$, besides the shielded chemical shifts of aromatic hydrogens, suggests an oxygenated substituent at $\mathrm{C}-4$. Also, the ${ }^{1} \mathrm{H}$ NMR spectrum showed a pair of downfield methylene hydrogens as triplet signals at $\delta 3.20\left(\mathrm{t}, J_{1^{\prime}, 2}, 4.9 \mathrm{~Hz}, \mathrm{H}-1^{\prime}\right)$ and $\delta 3.84\left(\mathrm{t}, J_{2^{\prime}, 1}, 4.9\right.$ $\mathrm{Hz}, \mathrm{H}-2$ '), each integrating to two hydrogens. The ${ }^{13} \mathrm{C}$ NMR spectrum analysis, in addition to the HMBC experiment data, disclosed the presence of seven carbons, including four aromatic $(\delta 163.0,132.9$, 123.7 and 115.9) and one deshielded signal $(\delta 170.9)$ attributed to the carbonylic group of amides, which showed long-range correlation to hydrogen at $\delta 7.89$.

Compound 2 was isolated as a colorless amorphous solid. Its molecular formula of $\mathrm{C}_{10} \mathrm{H}_{13} \mathrm{NO}_{4}$ was established by the ion at $\mathrm{m} / \mathrm{z}$ $212.0895[\mathrm{M}+\mathrm{H}]^{+}$in the HRESIMS spectrum. Theoretical mass of this compound is 212.0917 (error: $10 \mathrm{ppm}$ ). The ${ }^{1} \mathrm{H}$ NMR spectrum closely resembled that of compound $\mathbf{1}$. The main difference was assigned to the deshielded singlet at $\delta 3.46$, integrating to two hydrogens, and attributed to the methylene group attached at the benzene ring. These methylene hydrogens are correlated to the aromatic carbon at $\delta 130.8$ (C-2 and C-6) in the HMBC spectrum. These data explain aromatic hydrogens' shielded chemical shifts at $\mathrm{H}-2$ and $\mathrm{H}-6$ in comparison to the structure of compound $\mathbf{1}$.

Although these compounds are described herein for the first time, recently two hydroxybenzoic acid amides presenting similar structures were isolated from the roots of Bryonia aspera Stevex Ledeb. (Cucurbitaceae). ${ }^{14}$ This species is considered a medicinal plant traditionally used for cancer treatment, digestive and cardiac disorders, as well as for liver problems. ${ }^{15}$ The NMR data of 4-hydroxy$N$-(2-hydroxyethyl)-benzamide (bryonamide A) are in agreement with the data described here, except for the $\mathrm{C} 1$ ' chemical shift, which is more shielded in bryonamide A ( $\delta$ 43.5) than in compounds $\mathbf{1}$ and $\mathbf{2}$ ( $\delta 57.9$ and $\delta 57.2$, respectively). This effect probably occurs due to oxygen substitution in the $\mathrm{N}$ atom (hydroxyl amine group), which results in a deshielding effect on $\mathrm{Cl}^{\prime}$ '.

Hexane fraction from $B$. radicans resulted in the isolation of cholesterol (identified by NMR spectral data, compared with previous literature data) and other constituents (analyzed by GC-MS and NMR). The sub-fractions 1 and 2 were identified as hydrocarbon heptadecane (3) and the steroid biosynthetic precursor, squalene (4). The sub-fractions 3 and 5 presented the tetradecanoic (5) and hexadecanoic (6) acids, and the esters methyl hexadecanoate (7) and methyl 9-octadecenoate (8), respectively. The diterpenes trans-phytol (9) and neophytadiene
(10) were isolated and identified from sub-fraction 6. Moreover, the sub-fraction 7, further purified by TLC preparative, yielded the steroid cholesterol (11), the main steroid present in red algae.

Analyzing the ethyl acetate fraction, it was possible to identify a further nine structures (Figure 2): 4-(methoxymethyl)-phenol (12), 4-hydroxybenzaldehyde (13), methyl 4-hydroxybenzeneacetate (14), methyl 4-hydroxymandelate (15), methyl 2-hydroxy-3-(4hydroxyphenyl)-propanoate (16), hydroquinone (17), methyl 4-hydroxybenzoate (18), 4-hydroxybenzeneacetic acid (19) and (4-hydroxyphenyl)-oxo-acetaldehyde (20).

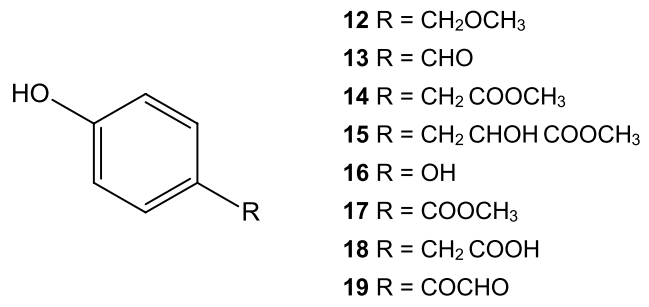

Figure 2. Aromatic compounds identified in marine red algae B. radicans

Regarding the occurrence of the identified metabolites, the esther methyl 4-hydroxymandelate has never been described as a natural product; although acid 4-hydroxymandelic was previously obtained from natural sources. ${ }^{16,17}$ Similarly, methyl 2-hydroxy-3-(4-hydroxyphenyl)-propanoate is known as an important endogenous cell growth-regulating agent; ${ }^{18}$ however there are no reports describing its occurrence in plants, microorganisms or marine sources. Conversely, some of the other phenolic compounds have been previously obtained from natural sources, but this is the first time their incidence in the marine environment is described; such as 4-(methoxymethyl)-phenol ${ }^{19}$ and (4-hydroxyphenyl)-oxo-acetaldehyde. ${ }^{20}$

Furthermore, to our knowledge, this is the first report of hydroquinone ${ }^{21}$ and methyl 4-hydroxybenzoate ${ }^{22}$ in the Rhodomelaceae family. The compounds methyl 4-hydroxybenzeneacetate ${ }^{23}$ and 4-hydroxybenzeneacetic acid ${ }^{24}$ are described here for the first time in Bostrychia genus. Recently, 4-hydroxybenzaldehyde, ${ }^{25}$ previously isolated from other marine sources, has been reported from Bostrychia tenella.

\section{EXPERIMENTAL}

\section{General procedures}

NMR spectra were recorded on a Bruker Avance DRX 500 FT spectrometer operating at 500 and $125 \mathrm{MHz}$ for ${ }^{1} \mathrm{H}$ and ${ }^{13} \mathrm{C} \mathrm{NMR}$, respectively. High resolution mass spectra were obtained on an UltrOTOF Bruker-Daltonics instrument (Billarica, USA) equipped with an ESI ion source (HRESIMS). The samples were dissolved in methanol/ 
water 4:1 (v/v) and infused into the ESI source at a flow-rate of $5 \mathrm{~mL}$ min $^{-1}$, using a Harvard Apparatus model 1746 (Holliston, MA) syringe pump. GC-MS analyses were performed on a Shimadzu QP2010 using a DB-5MS column, series number US7481543H (30 m, 0.25 mm i.d., $0.25 \mathrm{~mm}$ film thickness), Agilent technologies, Inc. USA. MS were recorded in electron ionization (EI) mode, with an ionization energy of $70 \mathrm{eV}$. Compounds analyzed by GC-MS were identified by comparison with retention indices (RI), calculated using alkanes from C9 to $\mathrm{C} 22$ (lot number 9673, Altech Associates, Inc USA), by association of mass spectra with a computer databank (Wiley 7 and NIST 62), and with published data in the literature. ${ }^{26}$ Chromatographic procedures were performed on silica gel 60 (230-400 mesh) and a Sephadex LH-20 column. Reversed phase semi-preparative HPLC separations were performed with a Shimadzu LC-6AD pump, using RP-18, 20 × $250 \mathrm{~mm}$, a $15 \mu \mathrm{m}$ particle size, Shimpack ODS(H) Kit, Shimadzu; with a flow rate of $9 \mathrm{~mL} \mathrm{~min}^{-1}$, monitoring at $270 \mathrm{~nm}$ with a Shimadzu Detector.

\section{Algae}

Specimens of red algae Bostrychia radicans were collected from the Rio Escuro mangrove (Ubatuba, São Paulo State, Brazil), in August 2007. Voucher specimens were deposited at the Herbarium of the Instituto de Botânica (São Paulo, São Paulo State, Brazil) with the following accession number: SP 365678. The fresh samples were stored at $-10{ }^{\circ} \mathrm{C}$ until required for analyses.

\section{Extraction and isolation}

The frozen material was milled with liquid nitrogen and extracted by maceration using methanol $(\mathrm{MeOH})$, at room temperature. The macerate was concentrated under reduced pressure to yield the methanolic extract $(4.8 \mathrm{~g})$. This extract was fractionated by means of liquid-liquid partition using hexane (Hex) and ethyl acetate (AcOEt) as solvents, yielding 3 fractions (hexane, ethyl acetate, and hydroalcoholic). The hexane fraction $(2.8 \mathrm{~g})$ was submitted to classic column chromatography (silica gel, 120.0 g) using Hex, AcOEt and $\mathrm{MeOH}$ as binary mixtures of increasing polarity. This procedure afforded 13 sub-fractions. Subsequently, preparative TLC was used to yield the compounds 3-11. The ethyl acetate fraction $(0.3 \mathrm{~g})$ was purified using a Sephadex LH-20 column, eluted with MeOH-AcOEt (7:3) yielding 14 sub-fractions. The sub-fractions were analyzed by spectrometric techniques resulting in the identification of compounds 12-20. These compounds were identified mainly by ${ }^{1} \mathrm{H}$ and ${ }^{13} \mathrm{C} N M R$ spectral data (comparison with previous literature data) and GC-MS analyses. The hydroalcoholic fraction $(0.4 \mathrm{~g})$ was submitted to SPE using $\mathrm{MeOH}$ and $\mathrm{H}_{2} \mathrm{O}$ in elution gradient. The $\mathrm{MeOH}-\mathrm{H}_{2} \mathrm{O}(2: 1)$ fraction was analyzed by RP-HPLC and two new amide derivatives (4-hydroxy- $N$-(2'-hydroxyethyl)-benzamide (1) and 4-hydroxy$-N$-(2'-hydroxyethyl)-benzeneacetamide (2) were isolated through RP-HPLC semi-preparative ( 0.9 and $1.1 \mathrm{mg}$, respectively). The solvent system used was: 0.1-15 min:3-5\% acetonitrile (ACN); 15-20 min:5-13\% ACN; 20-60 min:13-25\% ACN; 60-68 min:25-45\% ACN; 68-70 min:45-100\% ACN; 70-75 min:100\% ACN. Thus, the amide structures were assigned by NMR spectral data $\left(\mathrm{NMR}{ }^{1} \mathrm{H}, \mathrm{NMR}{ }^{13} \mathrm{C}\right.$, HMQC, HMBC and COSY) and MS.

\section{CONCLUSIONS}

This study provides the first description of the isolation and characterization of secondary metabolites from marine red algae Bostrychia radicans. The metabolites reported here (mainly the new amides and phenolic compounds) illustrate the chemical diversity within Bostrychia, an understudied genus belonging to the Rhodomelaceae family, generally known for the production of terpenes and halogenated phenolic compounds.

\section{ACKNOWLEDGEMENT}

The authors acknowledge FAPESP, CNPq and CAPES for financial support, J. C. Tomaz by MS analyses and Dr. N. Boralle by NMR experiments.

\section{REFERENCES}

1. Zuccarello, G. C.; West, J. A.; J. Phycol. 2003, 39, 948.

2. Eston, V. R.; Braga, M. R. A.; Cordeiro-Marino, M.; Fujii, M. T.; Yokoya, N. S.; Aquat. Bot. 1992, 42, 315.

3. Karsten, U.; Bock, C.; West, J. A.; Bot. Acta 1995, 108, 321.

4. Kim, G. H.; Shim, J. B.; Klochkova, T. A.; West, J. A.; Zuccarello, G. C.; J. Phycol. 2009, 44, 1519.

5. Zuccarello, G. C.; West, J. A.; NZJMFR 2008, 42, 315.

6. Kremer, B. P.; Biochem. System. Ecol. 1995, 4, 139.

7. Ascêncio, S. D.; Orsato, A.; França, R. A.; Duarte, M. E. R.; Noseda, M. D.; Carbohydr. Res. 1995, 341, 677.

8. West, J. A.; Zuccarello, G. C.; Hommersand, M.; Karsten, U.; Gors, S.; Phycol. Res. 2006, 54, 1.

9. Karsten, U.; Gors, S.; Eggert, A.; West, J. A.; Phycologia 2007, 46, 143.

10. Noseda, M. D.; Túlio, S.; Duarte, M. E. R.; J. Appl. Phycol. 1999, 11, 35 .

11. Duarte, M. E. R.; Noseda, D. G.; Noseda, M. D.; Túlio, S.; Pujol, C. A.; Damonte, E. B.; Phytomedicine 2001, 8, 53.

12. de Felício, R.; Yokoya, N. S.; Debonsi, H. M.; Quim. Nova 2008, 31, 837.

13. de Oliveira, A. L. L.; da Silva, D. B.; Turatti, I. C. C.; Yokoya, N. S.; Debonsi, H. M.; Biochem. Syst. Ecol. 2009, 37, 761.

14. Sahranavard, S.; Naghibi, F.; Siems, K.; Jenett-Siems, K.; Planta Med. 2010, 76, 1014.

15. Ghorbani, A.; J. Ethnopharmacol. 2005, 102, 58.

16. Botes, L.; Westhuizen, F. H.; Loots, D. T.; Molecules 2008, 13, 2169.

17. Grün, C. H.; van Dorsten, F. A.; Jacobs, D. M.; Le Belleguic, M.; van Velzen, E. J. J.; Bingham, M. O.; Janssen, H-G.; van Duynhoven, J. P. M.; J. Chromatogr., B: Anal. Technol. Biomed. Life Sci. 2008, 871, 212.

18. Markaverich, B. M.; Gregory, R. R.; Alejandro, M-A.; Varma, R. S.; Johnson, G. A.; Middleditch, B. S.; J. Steroid Biochem. 1989, 33, 867.

19. Heihachiro, T.; Itiro, Y.; Kazuo, Y.; Il Hyuk, K.; Chem. Pharm. Bull. 1981, 29, 55.

20. Qin, P.; Ma, T.; Wu, L.; Shan, F.; Ren, G.; J. Food. Sci. 2011, 76, 401.

21. Menzel, D.; Kazlauskas, R.; Reichelt, J.; Bot. Marina 1983, XXVI, 23.

22. Abdul Majeed, K.; Sumaira, N.; Zeba Parween, I.; Muhammad Iqbal, C.; Nat. Prod. Res. 2011, 25, 898.

23. Tasdemir, D.; Mangalindan, G. C.; Concepción, G. P.; Harper, M. K.; Ireland, C. M.; Chem. Pharm. Bull. 2001, 49, 1628.

24. Flodin, C.; Whitfield, F. B.; Phytochemistry 1999, 51, 249.

25. de Felício, R.; de Albuquerque, S.; Young, M. C. M.; Yokoya, N. S.; Debonsi, H. M.; J. Pharm. Biomed. Anal. 2010, 52, 763.

26. Adams, R. P.; Identification of Oil Components by Gas Chromatography/ Mass Spectroscopy, Allured Publ. Corp.: Carol Stream, 1999. 